\title{
Clinical and cytogenomic characterization of de novo trisomy 9 mosaicism in an Egyptian family: phenotype/ karyotype correlation
}

\author{
Hala T El-Bassyouni ${ }^{1 *}$, Marwa Shehab ${ }^{2}$, Azza E Abd-Elnaby ${ }^{2}$, Mohammed M Sayed-Ahmed ${ }^{1}$, Sanaa Kamal Mohamed ${ }^{3}$ and Manal Abd EL- \\ Salam $^{4}$ \\ ${ }^{1}$ Clinical Genetics Department, National Research Centre, Cairo, Egypt \\ ${ }^{2}$ Cytogenetics Department, National Research Centre, Cairo, Egypt \\ ${ }^{3}$ Biological Anthropology Department, Medical Research Division, National Research Centre, Cairo, Egypt \\ ${ }^{4}$ Pediatric Department, Faculty of Medicine (for girls) Al-Azhar University, Egypt
}

\begin{abstract}
Trisomy 9 mosaicism is a rare chromosome abnormality with developmental disabilities, delayed speech, facial dysmorphism and organ pathologies, the phenotype usually differs among individuals. This study presents a proband and his sib with mosaic trisomy 9 but the clinical manifestations of the boy were more severe than his sister as the number of abnormal cells were more in the boy, this could highlight the existence of phenotypic/karyotype correlation and the association of the level of mosaicism with the severity of the phenotype. This report expands the clinical manifestations of this chromosomal abnormality as multiple areas of hyperpigmentation were noticed in these cases that to the best of our knowledge have not been reported before.
\end{abstract}

\section{Introduction}

Trisomy 9 (T9) syndrome and trisomy 9 mosaicism are rare chromosomal disorders. Trisomy $9 \mathrm{p}$ may result from a parental reciprocal translocation between chromosome 9 and another autosome or may be due to a de novo non familial aberration. In the majority of cases, phenotypic variability occurs due to the variable size of the trisomic fragment and the frequent concomitant monosomy or trisomy [1]. Children born with T9 mosaicism usually survive into adulthood $[2,3]$. T9 mosaicism usually present with a low birth weight and a wide range of developmental disabilities, dysmorphism and organ abnormalities, though the phenotype may differ widely between the patients [4,5]. T9 mosaicism is characterized by growth retardation, developmental delay, delayed communication and speech and learning difficulties. The typical physical features include microcephaly, craniofacial abnormalities such as cleft palate, low set ears, loose joints, skeletal abnormalities of the skull, hands and feet [6].

Abnormalities involve different organ systems such as the brain and CNS, heart, kidneys, digestive tract, muscles (hypertonia), genital and urinary tract [5,7]. However, growth retardation and developmental delay were mainly less severe in patients with a low level of T9 mosaicism. NTRK2, DMRT1 and NTRKR2 recessive genes related to growth and development on chromosome 9, may also contribute to the overall clinical disease phenotype [3].

\section{Case report}

In this study, we report on two de novo sibs with variable phenotypic and clinical features of trisomy 9p. A 3-years old male patient, the first born of a healthy consanguineous couple was referred to our clinic for chromosomal analysis due to delayed milestones and dysmorphic features. The karyotype of the parents was normal. There was prenatal onset of growth deficiency. The dysmorphic features included triangular face, recession of anterior hair line, downwards slanting of eyes, bulbous nose, low set ears, micrognathia, short neck and clinodactly in the $5^{\text {th }}$ finger of the right hand. There were areas of hyperpigmentation on the face and abdomen. Anthropometric measurements revealed growth retardation as the head showed microcephaly $41.5 \mathrm{~cm}(-4.4 \mathrm{SD})$, the weight was $6 \mathrm{~kg}(-5 \mathrm{SD})$ and the height was short $73.5 \mathrm{~cm}(-3.9 \mathrm{SD})$. Cardiovascular abnormalities were patent foramen ovale, patent ductus arteriosus (PDA), and mild pulmonary hypertension. X-Rays of the left hand revealed hypoplastic terminal phalanges. Growth hormone levels before and after stimulation were normal. Abdominal and pelvic sonar and CT brain were normal. No fundus, kidney or genital, abnormalities were detected. Intellectual disability and delayed speech were detected. The karyotype of our patient revealed: 47,XY,+ 9, 45,XY, - 9, 47,XY,+ mar and 46,XY. After one year of admission, the parents got a daughter, but they did not seek prenatal diagnosis, then they brought her at the age of 3 years for consultation. She had delayed milestones, growth retardation and dysmorphic features but to a less extent than her brother, her echocardiogram was normal, the speech development was milder and her karyotype was 47,XX,+ mar and 46,XX.

*Correspondence to: Hala T El-Bassyouni, Clinical Genetics Department, National Research Centre, Cairo, Egypt, E-mail: halabassyouni@yahoo.com

Key words: trisomy 9 mosaicism, hyperpigmentation, dysmorphism, developmental delay, karyotype, language delay

Received: May 27, 2020; Accepted: June 12, 2020; Published: June 17, 2020 


\section{Patients and Methods}

Patients were assessed by full medical history, meticulous clinical examination, pedigree analysis, language evaluation and karyotype analysis.

Language evaluation was performed using the Modified Preschool Language Scale - Fourth (modified PLS-4) Arabic edition [8]; a language test, standardized on normal Arabic speaking children from Egypt. It is composed of two subscales; Auditory Comprehension and Expressive Communication subscale used mainly to identify children who have a language disorder or delay, with age range between 2 months till 7 years and 5 months, as well as elder children who function developmentally in this age range.

G-banding: Chromosomal analysis was performed on phytohaemagglutinin (PHA) - stimulated peripheral blood lymphocytes, then GTG-banding technique according to Verma and Babu [9], to record the presence of chromosome aberrations. Metaphases were analyzed and karyotyped following the International System for Human Cytogenetic Nomenclature [10]. Conventional cytogenetic results were further confirmed by Fluorescence in situ hybridization (FISH) according to Pinkle et al. [11].

Fluorescence in-situ hybridization (FISH) technique was applied on interphase and metaphase cells from peripheral blood according to modification of Pinkel et al. [11] by using Whole Chromosome Painting Prope (WCP) supplied by Cytocell Aquarius Diagnostics. The origin of the extra marker chromosome was identified and confirmed by FISH using Whole Chromosome Paint 9 probe (WCP9) spectrum green.

Written informed consent was obtained from the parents of the children for the publication of this report and any accompanying images.

\section{Results}

Table 1 summarizes the clinical findings of the studied patients. Testing of both parents revealed normal peripheral blood karyotypes denoting de novo non familial trisomy $9 \mathrm{p}$.

The pedigree of the family is presented in Figure 1. The dysmorphism and hyperpigmentation in the proband and the female sib (Figure 2).

The language skills of the two sibs were evaluated using the Modified Preschool Language Scale - Fourth (modified PLS-4) Arabic edition [8]. The male sib, aged 6 years and 1 month, revealed receptive language age equaling 5 years and 2 months (standard receptive language score $=52$ ), expressive language age equaling 4 years and 8 months (standard expressive language score $=53$ ), and total language age equaling 5 years and 1 month (standard total language age $=51$ ) Table 2 . The female sib, aged 2 years and 4 months, revealed receptive language age equaling 2 years and 5 months (standard receptive language score $=$

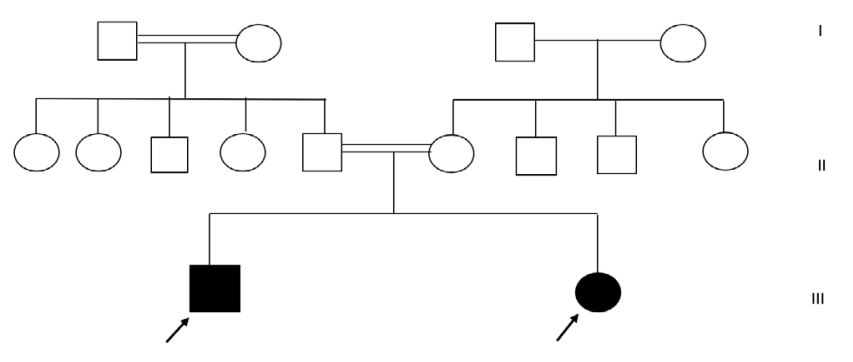

Figure 1. The pedigree of the family

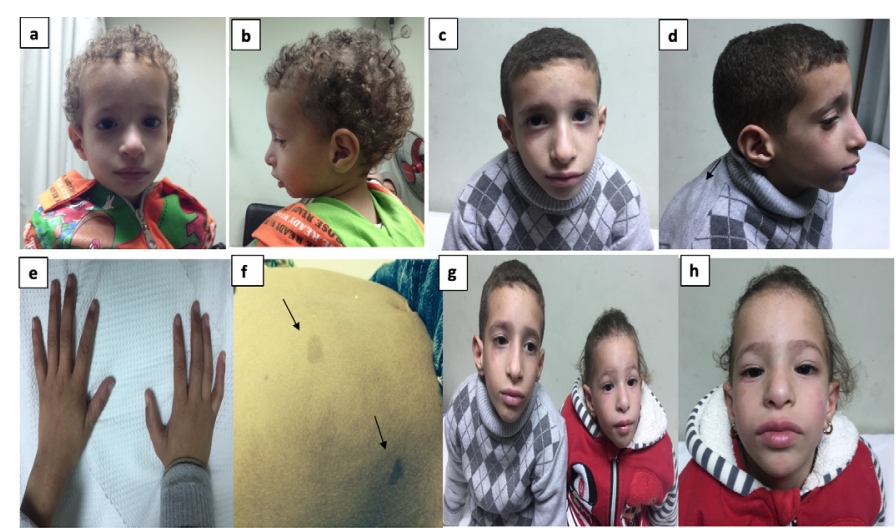

Figure 2. a and b: The patient at the age of 1 year and 5 months, $c$ and $d$ : the patient at the age of 7 years showing the dysmorphic features: microcephaly, broad forehead, downwards slanting of eyes, hemangioma under the right eye, full lips, large low set ears, bulbous nose, micrognathia, and short neck. e: areas of hyperpigmentation on the abdomen. f: clinodactly of $5^{\text {th }}$ finger in the right hand. $g$ and $\mathrm{h}$ : The patient and his sister with the same dysmorphism

Table 1. Summarizes the clinical findings of the studied patients

\begin{tabular}{|c|c|c|c|c|}
\hline $\begin{array}{c}\text { The Clinical } \\
\text { Characteristics }\end{array}$ & $\begin{array}{c}\text { Jones et } \\
\text { al. (2013) }\end{array}$ & $\begin{array}{l}\text { Pejcic et al. } \\
\quad \text { (2018) }\end{array}$ & The male sib & The female sib \\
\hline $\begin{array}{l}\text { Prenatal onset of } \\
\text { growth deficiency }\end{array}$ & + & + & + & + \\
\hline Broad forehead & + & + & + & + \\
\hline $\begin{array}{l}\text { Upslanting } \\
\text { of the eyes, } \\
\text { blepharophimosis }\end{array}$ & + & + & - & + \\
\hline Deeply set eyes & + & + & + & + \\
\hline Micrognathia & + & + & + & + \\
\hline Low set ears & + & + & + & + \\
\hline Facial asymmetry & - & + & + & + \\
\hline Short neck & + & + & + & + \\
\hline $\begin{array}{l}\text { Single palmar } \\
\text { crease }\end{array}$ & + & - & - & - \\
\hline Joint anomalies & + & + & - & - \\
\hline \multicolumn{5}{|l|}{$\begin{array}{l}\text { Other medical } \\
\text { conditions }\end{array}$} \\
\hline $\begin{array}{l}\text { Congenital heart } \\
\text { defect }\end{array}$ & + & + & + & + \\
\hline Hydrocephalus & - & + & - & - \\
\hline Hearing loss & - & + & - & - \\
\hline $\begin{array}{l}13 \text { ribs and thoracic } \\
\text { vertebrae }\end{array}$ & - & + & - & - \\
\hline $\begin{array}{l}\text { Genitourinary } \\
\text { anomalies }\end{array}$ & - & + & - & - \\
\hline $\begin{array}{l}\text { Areas of } \\
\text { hyperpigmentation }\end{array}$ & - & - & + & + \\
\hline Karyotype & & $\begin{array}{c}47, \mathrm{XY},+93 \% \\
46, \mathrm{XY} \quad 27 \%\end{array}$ & $\begin{array}{c}47, \mathrm{XY},+9 \quad 10 \% \\
45, \mathrm{XY},-910 \% \\
47, \mathrm{XY},+ \text { mar } 40 \% \\
46, \mathrm{XY} 40 \%\end{array}$ & $46, \mathrm{XX} 40 \%$ \\
\hline
\end{tabular}

Table 2. The modified PLS-4 Arabic edition in the male sib, with the chronological age of 6 years and 1 month

\begin{tabular}{|c|c|c|c|}
\hline Test domain & Language age & $\begin{array}{c}\text { Standard score } \\
\text { (mean=100 } \pm \\
\mathbf{2 2 . 5}\end{array}$ & $\begin{array}{c}\text { Degree of language } \\
\text { delay }\end{array}$ \\
\hline Receptive language & 5 years, 2 months & 52 & moderate \\
\hline Expressive language & 4 years, 8 months & 53 & moderate \\
\hline Total language & 5 years, 1 month & 51 & moderate \\
\hline
\end{tabular}

105), expressive language age equaling 2 years and 2 months (standard expressive language score $=98$ ), and total language age equaling 2 years and 3 months (standard total language age $=103$ ) Table 3. 
The karyotype analysis of the male sib was: $47, \mathrm{XY},+9$ in $10 \%$, $45, \mathrm{XY},-9$ in $10 \%, 47, \mathrm{XY},+$ mar in $40 \%$ and $46, \mathrm{XY}$ in $40 \%$ of the studied cells (Figures 3a, $3 \mathrm{~b}$ and 4 ).

The karyotype analysis of the female sib was: $46, \mathrm{XX}$ in $60 \%$ of the studied cells and 47,XX,+ mar in $40 \%$ of the cells (Figure 5).

Table 3. The modified PLS-4 Arabic edition in the female sib, with the chronological age of 2 years and 4 months

\begin{tabular}{|c|c|c|c|}
\hline Test domain & Language age & $\begin{array}{c}\text { Standard score } \\
\text { (mean=100 } \mathbf{2 2 . 5})\end{array}$ & $\begin{array}{c}\text { Degree of } \\
\text { language delay }\end{array}$ \\
\hline Receptive language & 2 years, 5 months & 105 & Average \\
\hline $\begin{array}{c}\text { Expressive } \\
\text { language }\end{array}$ & 2 years, 2 months & 98 & Average \\
\hline Total language & 2 years, 3 months & 103 & Average \\
\hline
\end{tabular}

Conventional cytogenetic results were further confirmed by Fluorescence in situ hybridization (FISH).

The origin of the extra marker chromosome was identified in the male sib (Figure 6a) and the female sib (Figure 6b) and confirmed by molecular cytogenetic analysis FISH according to Pinkle et al. [11] using Whole Chromosome Paint 9 probe (WCP9) spectrum green.

\section{Discussion}

Our patients had prenatal onset of growth deficiency similar to that reported by Jones et al.; Pruksanusak et al. and Pejcic et al. [2,5,12]. They presented with delayed milestones and dysmorphic features comprising triangular face, recession of anterior hair line, downwards slanting of eyes, bulbous nose, low set ears, micrognathia, short neck

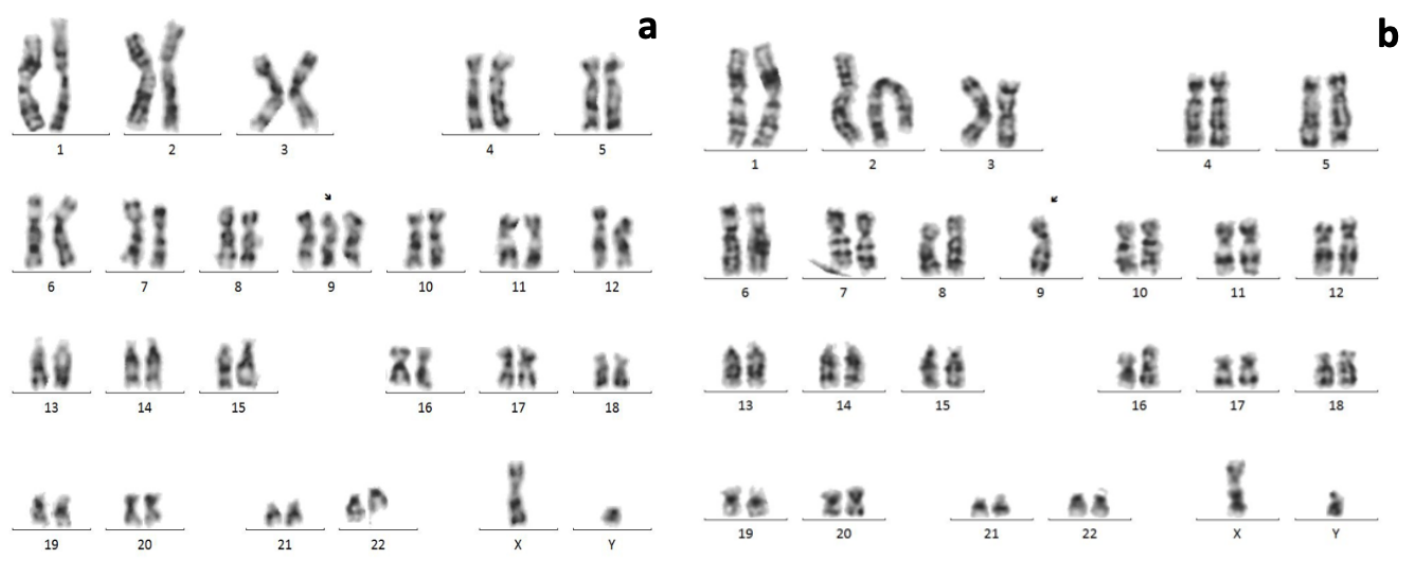

Figure 3. The karyotype analysis of the male sib showing $47, \mathrm{XY},+9$ in (3a) while (3b) shows $45, \mathrm{XY},-9$
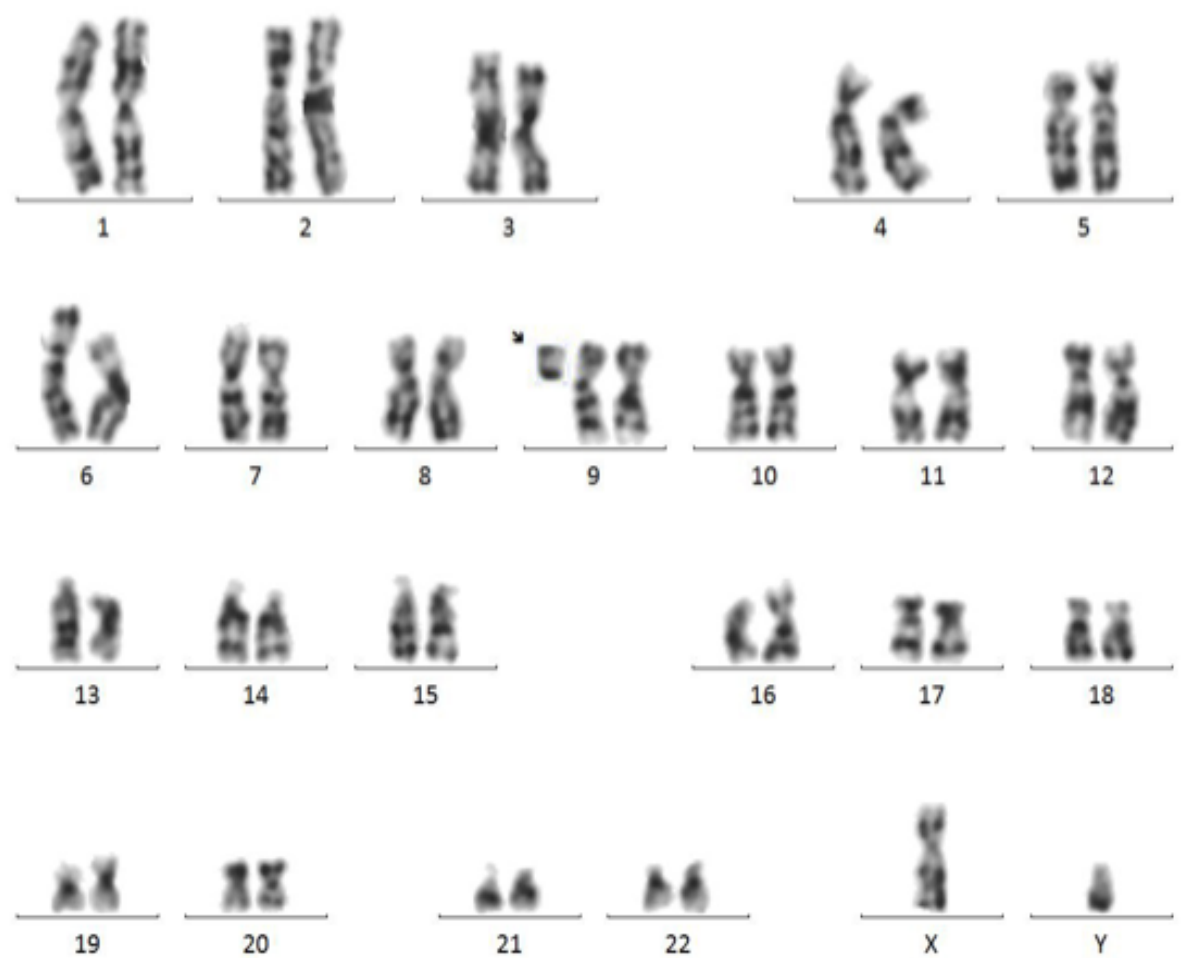

Figure 4. The karyotype analysis of the male sib showing $47, \mathrm{XY},+$ mar 

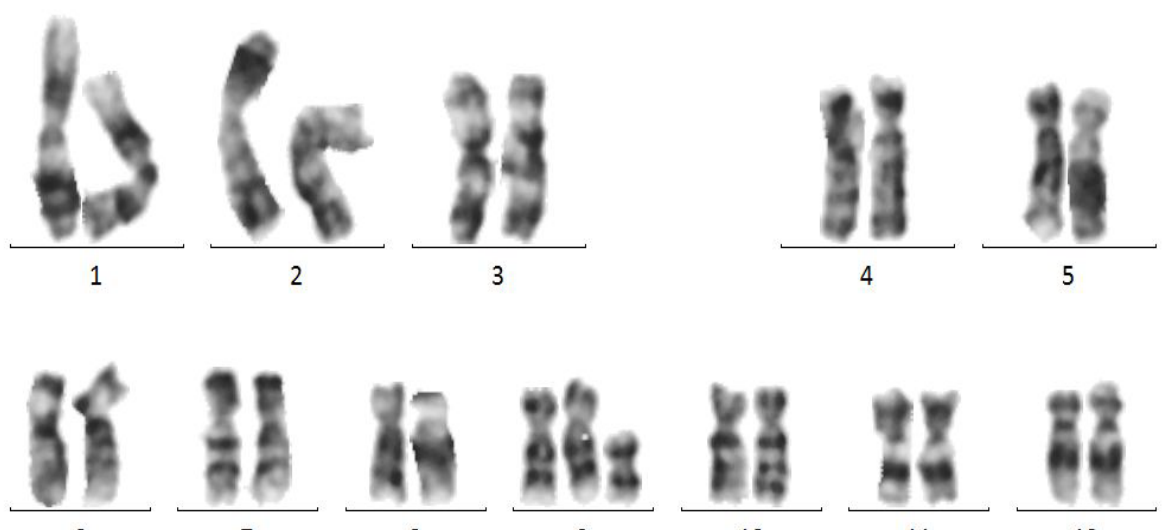

6

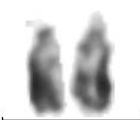

13

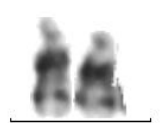

14
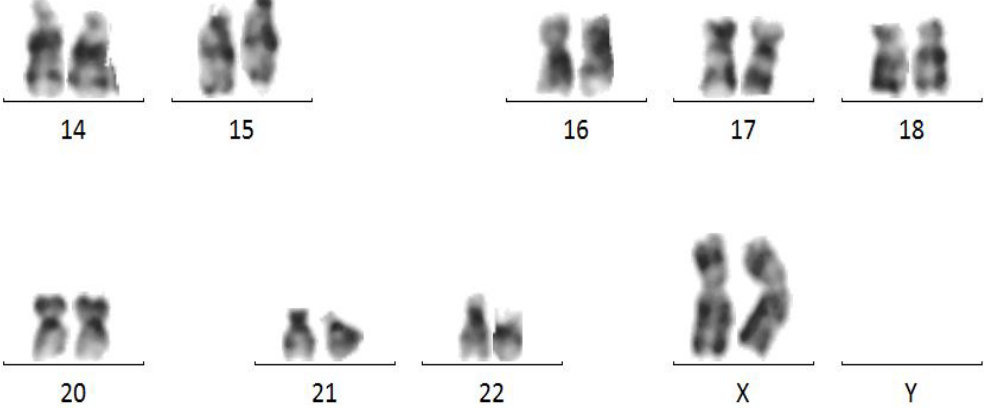

Figure 5. The karyotype analysis of the female sib showing $47, \mathrm{XX},+$ mar
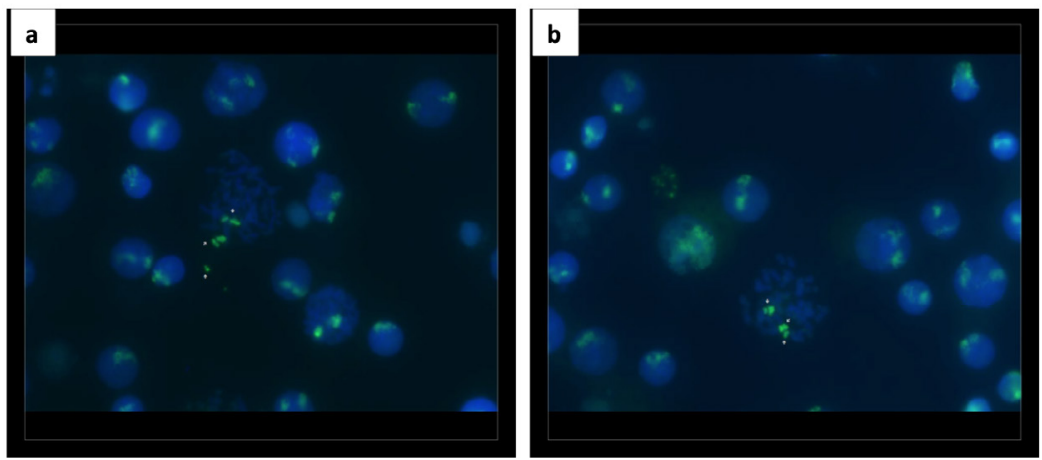

Figure 6. FISH using WCP 9 on metaphase showing the origin of marker chromosome 9, (a): in the male sib, (b): in the female sib

and clinodactly of $5^{\text {th }}$ finger in right hand. Schinzel [13] suggested that the pattern of radiographic findings in trisomy $9 p$ appears to be unique among chromosome aberrations. Roentgenograms of the skeleton demonstrated hypoplastic pubic bones, and bilateral hypoplastic distal phalanges of the feet, pes valgus and bilateral clinodactly of both 5th fingers [14]. Both sibs presented with hypertelorism with downwards slanting of the eyes, similarly, Dhangar et al. [15] affirmed hypertelorism in their patient. Although our patients did not have hearing loss, Zhou et al. [16] and Dhangar et al. [15] described a trisomy 9 patient with sensorineural hearing loss and proposed that $9 \mathrm{q} 13 \rightarrow 9 \mathrm{q} 21$ region may be responsible for hearing. This may be because the critical region of trisomy 9 in our cases was different. Also, they found clinodactly of both of the 5th fingers, a bilateral simian crease, joint hyperlaxity and hypoplasia of the toenails, however the male sib had hypoplastic terminal phalanges and clinodactly of the fifth finger on the right hand while, his sister did not have any bone abnormality. Wilson et al. [17] reported that the clinical severity in trisomy $9 p$ generally associates with the extent of trisomic chromosome material. However, De Ravel et al. [18] narrowed the critical region of trisomy $9 p$ phenotype between 9 p22.1 and 9p22.2. Our studied cases revealed trisomy of the distal part of the short arm of chromosome 9.

Our patient and his sister presented with areas of hyperpigmentation, which to the best of our knowledge was not reported before. They also had short neck comparable to that reported by Brambila et al. [7] and Zhou et al. [13]. The echocardiogram displayed patent foramen ovale, patent ductus arteriosus (PDA), and mild pulmonary hypertension in the male sib but not in his sister, this may be due to the increased number of affected cells in the proband compared to his sib. While, Tonni et al. [4] noted that the cardiovascular abnormalities were characterized by a right-sided, $\mathrm{U}$-shaped aortic arch associated with a ventricular 
septal defect (VSD). On the contrary, Zhang et al. [14] did not find any cardiac abnormality. Furthermore, our male sib had growth retardation and intellectual disability more than that in the female sib, analogous to previous investigators findings $[14,15,19]$. The incidence and severity of the malformation and the intellectual disability correlates with the percentage of trisomic cell [12]. This may emphasize that patients with a high percentage of affected cells (high mosaicism) might have more severe symptoms than those with a low percentage of affected cells (low mosaicism). Although, Ma et al. [3] claimed the lack of phenotypic/genotypic correlation and absence of correlation of the level of mosaicism with the severity of the disease phenotype. Haddad et al. [20] stated that, Trisomy 9 patients are more severe and variable in their phenotype than partial trisomy 9 patients. The genes associated with growth and development on Chromosome 9 as DMRT1, NTRK2 and NTRKR2 may have led to the growth retardation [3]. The growth hormone levels before and after stimulation were normal in our patients. Though, Tiong et al. [21] stated that his patient had growth hormone deficiency. Abdominal and pelvic sonar was normal in both patients although, Tonni et al. [4] reported multicystic dysplastic kidney disease in their study.

CT brain of both patients were normal, this corroborates with the findings of Zhang et al. [14]. Whereas, Tonni et al. [4] found hypoplastic corpus callosum, and a Dandy-Walker malformation in their study.

The range and severity of the phenotype relies on the percentage of cells with extra chromosome 9 [15]. Speech development was severely retarded in the proband but was milder in his sister, Gulten et al. [21] and Bruns and Campbell [19] noted delay in language, communication and social-emotional development.

Speech development in the male sib showed a moderate delay in his total language skills, especially in the expressive domain, while the female showed average language skills. This diversity in language skills was recorded in several studies describing trisomy 9 mosaicism $[6,16,22]$. However, the young female sib should be followed up to delineate any delay in her language skills in the future.

Mosaic trisomy 9 appears to result from errors of chromosomal separation during meiosis or occur during mitosis, these abnormalities are known as a "pericentric inversion" in one of the parents. Cytogenetic studies allow the differentiation of several mechanisms causing trisomy $9 \mathrm{p}$ [23]. The karyotype of the proband was confirmed as $47, \mathrm{XY},+9$; 45,XY, - 9 and 47,XY,+ mar and 46,XY while his sister karyotype was $47, \mathrm{XX},+$ mar and 46,XX similar to Luo et al., Tong et al. [24,25]. FISH is a focused and targeted approach for diagnosing mosaic trisomy facilitating genetic counseling and prevention of the birth of further affected offspring. In our study, the mother did not come for prenatal diagnosis during the pregnancy of her daughter. The accompanying features in trisomy 9 usually depend on the percentage of trisomic cells. Therefore, the clinical presentation of the proband was more severe than his sib.

Conclusion: Trisomy 9 mosaicism comprises a wide spectrum of congenital abnormalities, the present study broadens the phenotype of this rare aneuploidy, multiple areas of hyperpigmentation were noticed in these cases that to the best of our knowledge have not been reported before. Furthermore, a phenotype/karyotype correlation was revealed. Chromosome studies and genetic counselling are typically recommended for parents with an affected child.

\section{Competing interests}

The authors declare that they have no competing interests.

\section{References}

1. Tonni G, Grisolia G (2013) Ultrasound diagnosis of central nervous system anomalies (bifid choroid plexus, ventriculomegaly, Dandy-Walker malformation) associated with multicystic dysplastic kidney disease in a trisomy 9 fetus: case report with literature review. J Clin Ultrasound 41: 441-447.

2. Pruksanusak N, Rujirabanjerd S, Kanjanapradit K, Kor-anantakul O, Suntharasaj T, et al. (2014) Prenatal diagnosis of complete trisomy 9 with a novel sonographic finding of heart calcification. J Ultrasound Med 33: 1871-1873.

3. Ma J, Cram DS, Zhang J, Shang L, Yang H, et al. (2015) Birth of a child with trisomy 9 mosaicism syndrome associated with paternal isodisomy 9: A case of a positive noninvasive prenatal test result unconfirmed by invasive prenatal diagnosis. Mol Cytogenet 8: 44

4. Zhang G, Lituania M, Chitayat D, Bonasoni MP, Keating S, et al. (2014) Complete trisomy 9 with unusual phenotypic associations: Dandy-Walker malformation, cleft lip and cleft palate, cardiovascular abnormalities. Taiwan J Obstet Gynecol 53: 592-597.

5. Pejcic L, Stankovic T, Ratkovic-Jankovic M, Vasic K, Nikolic I (2018) Clinical manifestations in trisomy 9 mosaicism. Turk J Pediatr 60: 729-734.

6. Miryounesi M, Dianatpour M, Shadmani Z, Ghafouri-Fard S (2016) Report of a case with trisomy 9 mosaicism. Iran J Med Sci 41: 249-252.

7. Brambila-Tapia AJ, Neira VA, Vásquez-Velásquez AI, Jimenez-Arredondo RE, Chávez-González EL, et al. (2014) Pure 9p trisomy derived from a terminal balanced unreciprocal translocation. Genet Couns 25: 289-297.

8. El-Sady RS, El-Shoubary MA, Hafez GN, Mohammad AA (2011) Standardization, translation and modification of the preschool language scale-4. Unpublished doctoral thesis, Faculty of Medicine. Ain Shams university, Cairo, Egypt.

9. Verma RS, Babu A (1995) Human chromosomes principles and techniques. 2ed edn New York: McGraw-Hill.

10. Seabright M (1971) A rapid technique for human chromosomes. Lancet 11: 971-972.

11. Pinkel D, Gray J, Trask B, et al. (1986) Cytogenetic analysis by in situ by hybridization with fluorescently labeled nucleic acid propes. Cold Spring Harb Symp Quant Biol 51: 151-157. [Crossref]

12. Jones KL, Jones MC, Del Campo M (2013) Trisomy 9 mosaicism. Smith's recognizable patterns of human malformation, 7e. Philadelphia: Elsevier Saunders.

13. Schinzel A (1979) Trisomy 9p, a chromosome aberration with distinct radiologic findings. Radiology 130: 125-133.

14. Zhang J, Li H, Jiang S, Li H, Zhang Y (2015) Systematic genetic analysis for a case with duplication 9p. Zhonghua Yi Xue Yi Chuan Xue Za Zhi 32: 237-239.

15. Dhangar S, Korgaonkar S, Vundinti BR (2019) Partial trisomy 9 (9pter- $>9 \mathrm{q} 22.1$ ) and partial monosomy $14(14$ pter- $>14 \mathrm{q} 11.2)$ due to paternal translocation $\mathrm{t}(9 ; 14)$ (q22.1;q11.2) in a case of Dysmorphic features. Intractable Rare Dis Res 8: 72-77.

16. Zhou YC, Zhang C, Zhai JS, Li TF, Wu QY, et al. (2015) A patient with unusual features and a $69.5 \mathrm{Mb}$ duplication from a de novo extra der (9): a case report. Mol Med Rep 12: $155-158$.

17. Wilson GN, Raj A, Baker D (1985) The phenotypic and cytogenetics spectrum of partial trisomy 9. Am J Med Genet 20: 277-282.

18. De Ravel TJL, Fryns JP, Van Driessche J, Vermeesch JR (2004) Complex chromosome rearrangement $45, \mathrm{X}, \mathrm{t}(\mathrm{Y} ; 9)$ in a girl with sex reversal and mental retardation. $A m J$ Med Genet 124: 259-262.

19. Bruns DA, Campbell E (2015) Twenty-five additional cases of trisomy 9 mosaic: Birth information, medical conditions, and developmental status. Am J Med Genet Part A 167A: 997-1007.

20. Haddad BR, Lin AE, Wyandt H, Milunsky A (1996) Molecular cytogenetic characterization of the first familial case of partial trisomy 9p duplication (p22p24). $J$ Med Genet 33: 1045- 1047.

21. Tiong K, Cotterill A, Falhammar H (2010) Adult case of partial trisomy 9q. BMC Med Genet 11: 26.

22. Gulten T, Gorukmez O, Gorukmez O, Karkucak M, Ture M, et al. (2016) Another small supernumerary marker chromosome derived from chromosome 9 in a Klinefelter patient. West Indian Med J 61: 924-927.

23. Concolino D, Cinti R, Moricca M, Andria G, Strisciuglio P (1998) Centric fission of chromosome 9 in a boy with trisomy 9p. Am J Med Genet 79: 35-37. 
El-Bassyouni HT (2020) Clinical and cytogenomic characterization of de novo trisomy 9 mosaicism in an Egyptian family: phenotype/karyotype correlation

24. Luo Y, Chen S, Li H, Pan L, Shen M, et al. (2014) Detection of mosaic trisomy 9 missed by conventional cytogenetics using SNP-array and fluorescence in situ hybridization. Zhonghua Yi Xue Yi Chuan Xue Za Zhi 31: 469-471.
25. Tong Y, Yan S, Shi J, Chen L, Wan C, et al. (2018) Genetic analysis of an infant with duplication 9q34 syndrome. Zhonghua Yi Xue Yi Chuan Xue Za Zhi 35: 437439

Copyright: (C2020 El-Bassyouni HT. This is an open-access article distributed under the terms of the Creative Commons Attribution License, which permits unrestricted use, distribution, and reproduction in any medium, provided the original author and source are credited. 